\title{
REPORT ON THE INTERNATIONAL ASTIN/AFIR COLLOQUIA 1997
}

The 28th ASTIN International Colloquium and the 7th International AFIR Colloquium were held in the same week from August 11th to August 15th 1997, in the Cairns International Hotel, North Queensland, Australia. This first ever joint meeting culminated in a "joint day" on the Wednesday, recognising the fact that ASTIN and AFIR delegates have an increasing number of interests in common and that both actuarial and financial skills are necessary to cope with the new challenges of today. The CNN announcement of the merger of the Winterthur Insurance Company and the Crédit Suisse Group, news of which spread rapidly among delegates, emphasised this point.

The joint meeting was also an excellent opportunity to celebrate the 100th anniversary of the Institute of Actuaries of Australia. The first gathering of Australian actuaries to discuss the formation of an institute took place on August 12th 1897.

This historic meeting (and possibly also the chance to visit the Great Barrier Reef and the tropical rainforest, two of Australia's World Heritage Areas) attracted a large audience : 193 people registered for ASTIN and 209 registered for AFIR; both numbers include 126 people who took the opportunity to register for both colloquia. The delegates came from 31 different countries with groups of at least ten delegates from Australia, Belgium, Canada, Denmark, Germany, Japan, Netherlands, Norway, Sweden, Switzerland, United Kingdom and the USA.

Eight internationally recognised keynote speakers gave lectures during the week; 21 speakers presented papers during the two ASTIN days, nine during the afternoon of the joint day; 31 speakers presented their research, partly in concurrent sessions, during the two AFIR days. The combined proceedings of both colloquia have an approximate length of two thousand pages. Obviously, we can only mention the general themes and some highlights of the colloquia, which reflect our personal tastes and understanding.

The ASTIN colloquium opened with a session on the topical subject of catastrophe risk. Bruce Harper held an entertaining invited address on the modelling of wind hazards and insurance risks in Australia. This talk was impressive in showing how, in the absence of reliable data on the losses caused by tropical storms, insurance events could be simulated using physical models for storms and for the damage caused by storms with different characteristics.

In the second invited address Prof. Paul Embrechts, ETH Zürich, outlined the possibilities offered by extreme value theory in the modelling of catastrophic losses in the situation where some data are available. The basic message of extreme value theory is that there are natural probability distributions and models for extremely large observations in the same way that there are natural models for average values (such as the well known Gaussian normal distribution). Further contributed talks on extreme values by Alexander McNeil and Dietmar Pfeifer indicated that this 
interesting branch of probability theory is now coming to the attention of practising actuaries.

A second major topic on the first day was classification of risks, and this session showed the broad palette of statistical techniques now being used in insurance research. Talks ranged from the application of cluster analysis in the formation of tariff classes using neural network-based implementations to the evaluation of occupational risks using methods from survival analysis. Greg Taylor, who later in the week became the recipient of the first ever gold medal of the Institute of Actuaries of Australia, submitted two papers in this section, one on the use of Whitaker spatial smoothing to obtain good estimates of risks which vary geographically, the second on the setting up of a bonus-malus scale of premiums in the presence of additional rating factors.

The final session of the day consisted of papers on the subject of premium rating in which one identifiable theme was the use of Markov state models. Papers presented by Jose Garrido and by Ermanno Pitacco addressed the use of such models in disability and health insurance tarification. The day ended with delegates enjoying dinners at one of two exotic locations. One party sampled traditional Queensland fare at the Riverstone Homestead, a historical sugar plantation house; a second group dined at the luxury Paradise Palms Golf Course.

In view of the copiousness and excellence of the food and wine it was all the more remarkable that attendance had not declined on the second morning when delegates reconvened to hear talks in two sessions entitled statistics and reserving. In the former session David Dickson described an alternative to the classical compound Poisson risk process; he derived results for the probability and the extent of ruin when claims occur as more general renewal processes. In the latter session two papers looked at different aspects of the calculation of development factors, or link ratios, in the loss development problem. The first paper by Glen Barnett and Ben Zehnwirth focused on the use of diagnostics in the selection of competing models for loss development; the second paper by Erhard Kremer looked at a robust version of the classical chain-ladder model. After these short but intensive scientific sessions delegates spent the afternoon on an enjoyable excursion with the Kuranda historical railway from the coast up to Kuranda, passing the Barron Falls, and down again with Skyrail above the canopy of the tropical rainforest. This provided a most unusual but congenial backdrop for the important conference activity of catching up and networking with colleagues.

The joint ASTIN/AFIR day was mainly devoted to the securitization of insurance risk, the issue which best represents the convergence of ASTIN and AFIR interests. The first keynote lecture by James A. Tilley addressed the securitization of catastrophic property risks, the second by Prof. Neil Doherty, University of Pennsylvania, was about financial innovation in the management of catastrophe risk.

For ASTIN delegates the first talk followed nicely from the discussion of catastrophe risk on day one. The interest in securitization arises because of increased exposure to catastrophes and the empirical observation that frequency and severity of large losses are on the increase. Insurance companies alone may not have the capacity to handle the mega-catastrophes of the future. 
A possible way to pass the insurance risk to investors (in return for a corresponding risk premium) are catastrophe bonds. Investors can use these bonds to diversify their portfolios because natural disasters, for example, have a very small correlation with financial market risk. Catastrophe bonds can be classified as:

- pure catastrophe bonds, when the principal and the coupons are at risk;

- principal-protected catastrophe bonds, when only the coupons are at risk;

- deferred catastrophe bonds, when no payment as such is at risk, but the date of the payments can be deferred, leaving the issuer of the bond an interest gain in case of a catastrophe.

James Tilley described some products which have so far been developed, such as the California Earthquake Authority risk bonds (an example of the second type of bond above), and looked at reasons why the market for securitized products has generally developed slowly. Among these reasons are the favourable catastrophe experience since 1994, the rehabilitation of Lloyds and the weaknesses of proposed securitization structures. However, he suggested there was still a potential need for cost efficient products with flexible annual renewal possibilities and more of the simplicity which makes traditional reinsurance arrangements appealing.

In the afternoon presentations of the joint day, several points raised in the keynote lectures were studied more deeply. The correspondence of catastrophe bonds and defaultable bonds was discussed, both leading to an incomplete market setting which causes difficulties in the pricing methodology. An approach, advocated by Prof. Martin Schweizer, is to decompose the risk of say a catastrophe bond into a hedgeable part and a residual part, which is treated by standard actuarial methods to obtain a price. This leads to a bid-ask price spread for the catastrophe bond. A specific principal-protected catastrophe bond, the Winterthur Insurance convertible bond with WinCat coupons "hail", was considered by Uwe Schmock and several methods for the estimation of the coupon values were presented; model risk for the statistical analysis and the corresponding pricing of the bond were investigated. Further talks addressed selected topics of asset liability modelling, risk-based capital allocation, risk-adjusted performance management and reserving for future claims taking stochastic interest rates into account.

The joint day ended with a lavish ASTIN/AFIR colloquia banquet in the Great Hall of the Cairns Convention Centre, where a gold medal of the Institute of Actuaries of Australia was awarded to Greg Taylor, the chairman of the ASTIN scientific committee.

The first pure AFIR day started with Prof. Phelim Boyle's keynote lecture on quasi-Monte Carlo methods for numerical integration. He showed that deterministic low discrepancy sequences outperform crude Monte Carlo methods in low dimensions, but that this superiority diminishes for high dimensions or discontinuous integrands. Randomisation of low discrepancy sequences and reduction of the effective dimension of the integration problem can come in handy in these cases.

After morning tea, the AFIR prize winning papers were presented and the certificates awarded. The first prize was given to Glen R. Harris, AMP Society, Australia, for his paper on "Regime switching vector autoregressions: a Bayesian Markov chain Monte Carlo approach". The second prize was divided between D.J.F. Nonnenmacher and Jochen Russ, University of Ulm, Germany, for their 
paper "Equity-linked life insurance in Germany: quantifying the risk of additional policy reserves" and Ken Seng Tan and Prof. Phelim Boyle, University of Waterloo, Canada, for their paper "Applications of scrambled low discrepancy sequences to exotic options".

Prof. Stanley Pliska, University of Illinois, gave his keynote lecture on a model for risk-sensitive dynamic asset allocation. For measuring the performance of the model, he presented various infinite-horizon criteria: expected growth rate of the portfolio, expected utility growth rate of the portfolio and a risk-sensitive growth rate criterion. A major aim of this model was to combine the statistical work for parameter estimation with the forecast for asset management. Applied to a historic data set, the corresponding management strategy showed an impressive performance.

Several contributed talks also presented and compared asset/liability management strategies for various settings such as continuous-time pension fund models or portfolios of defaultable assets. Some further themes ranged from inflation modelling to an axiomatic classification of usurious loans and tax-efficient, option-based compensation packages for employees.

The last day of the colloquium started with the keynote lecture by Prof. J. David Cummins, University of Pennsylvania, about the use of financial derivatives in corporate risk management, participation and volume decisions in the insurance industry. According to this talk, the main reasons for the use of derivatives in the insurance industry are to avoid:

- financial distress costs like bankruptcy costs, additional regulatory restrictions and reputational losses affecting relationships with key employees, suppliers and customers ;

- duration problems in the asset/liability management, including the liquidity risk of private placements or real estate;

- foreign exchange risk, and

- losses due to the convexity of income tax schedules.

In the contributed talks on Friday, partly in concurrent sessions, Peter Antal applied ideas mentioned on the joint day to the pricing of regular options, arguing that option prices should contain a risk premium in any case because a dynamic hedge as in the Black-Scholes model is not possible in practice. Godfrey Perrott presented policyholder considerations for the demutualisation of a company. David Wilkie showed that different prices of risk and different portfolios cause a failure of the capital asset pricing model in a multi-currency world. Robert Clarkson critically discussed the financial risk in the Markowitz and Black-Scholes worlds, explaining that investors would not accept a certain level of risk (bankruptcy for example), no matter how high the offered risk premium is; a comparison with the risk of death in some dangerous sports made his point clear. Further talks concerned the fitting of the term structure, pricing rate of return guarantees, the use of genetic algorithms, the Italian pension plan or the social security system in Indonesia, for example.

The final keynote lecture was given by Dato' Abdul Khalid bin Ibrahim, currently the Group Chief Executive of Kumpulan Guthrie Berhad. He gave an overview of the Asian capital markets with special focus on the development of the capital markets in Malaysia and Singapore, and he encouraged the audience to invest in 
these markets. The colloquium closed with the annual general meeting of the AFIR section.

We close with a glimpse of future events. The 8th International AFIR Colloquium will take place in Cambridge, United Kingdom, 15th to 17th of September 1998. Write to David Golder, AFIR 1998 Colloquium Secretariat, Institute of Actuaries, Staple Inn Hall, London, WCIV 7QJ, United Kingdom, for information. The next General Insurance Convention \& ASTIN Colloquium will take place in Glasgow, Scotland, 7th to 10th of October 1998. For information write to Linda Pritchard at the above address. The next joint International ASTIN and AFIR Colloquia are scheduled to take place in Tokyo, Japan, from 22nd to 25th of August 1999, followed by the Centenary Convention 29th to 31st of August.

Alexander McNeIL and Uwe Schmock

Department of Mathematics

ETHZ, Zürich

Switzerland 